\title{
The influence of limited scope formulae on children's subject-copula combinations
}

\author{
Colleen E. Fitzgerald' ${ }^{1}$, Amanda M. Spangenberg ${ }^{1,2}$ \\ ${ }^{1}$ Department of Communication Sciences and Disorders, Bowling Green State University, Bowling Green, $\mathrm{OH}_{1}{ }^{2}$ Sandusky City School District, \\ Sandusky, OH, USA
}

Purpose: Children acquiring English use copula forms in formulaic constructions (e.g., it's) before using copula forms accurately with a variety of sentence subjects. Children may be susceptible to relying on copula forms learned by rote when the copulas they hear in parent input are frequently formulaic.

Methods: In this investigation, copulas in parent input to typically developing, English-speaking toddlers were classified by whether they were contracted to the sentence subject and by whether that subject was pronominal or lexical. Children's growth in copula productivity between 27 and 33 months of age was measured by quantifying combinations of copula am, are, is, was, and were with unique subjects.

Results: Parents' use of copula is with contraction to pronominal subjects outnumbered uses with lexical subjects or without contraction. Parents' use of the less common copulas, with low-frequency lexical subjects or without contraction to the subject, was significantly positively related to children's subsequent growth in unique subject+copula combinations. However, parents' use of copulas contracted to pronouns was not related to children's copula productivity.

Conclusions: These findings hold implications for understanding how children make use of grammatical information in parent input, for how to measure children's grammatical growth, and for enhancing the copula input provided by clinicians and parents.

Keywords: Parent input, Morphology, Language acquisition, Grammar, Copula

\section{INTRODUCTION}

In the study of child language acquisition, it is traditional to compare children's attempts at sentences to what adults consider grammatical. When children do not produce a particular structure that adults would consider obligatory, these omissions are seen as a reflection of the child's grammatical knowledge or competence at that time. Historically, children typically acquiring language have been described as initially omitting grammatical morphemes that carry information for tense and agreement (i.e., finiteness). Children then inconsistently include those morphemes, and ultimately use them with adult-like accuracy [1]. These morphemes include the copula and auxiliary $\mathrm{BE}$ (i.e., am, is, are, was, were), third singular -s, past tense - $e d$, and auxiliary DO (i.e., do, does, did). The observation that children use these morphemes optionally before reaching adult-like use has been attested cross-linguistically in typical development and is also true of children with language disorders [2-4].

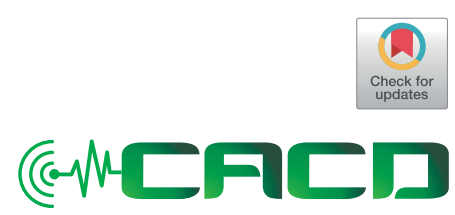

Received: July 14, 2019

Revision: August 16, 2019

Accepted: August 16, 2019

Correspondence:

Colleen E. Fitzgerald

Department of Communication Sciences and Disorders, Bowling Green State University, 200 Health and Human Services Building, Bowling Green, $\mathrm{OH}$ 43403, USA

Tel: +419-372-7182

Fax: +419-372-8089

E-mail: cefitzg@bgsu.edu

(C) 2019 The Korean Association of SpeechLanguage Pathologists

This is an Open Access article distributed under the terms of the Creative Commons Attribution NonCommercial License (http://creativecommons.org/ licenses/by-nc/4.0/) which permits unrestricted noncommercial use, distribution, and reproduction in any medium, provided the original work is properly cited. 
Typically developing toddlers acquiring English provide evidence that tense and agreement morphemes develop in a predictable sequence. Children use copula is in multiple unique sentences before the other tense morphemes such as past tense - $e d$ and auxiliaries emerge [5,6]. Furthermore, tense and agreement morphemes develop systematically with correct uses of the copula relating to accurate uses of the later developing morphemes through cross-morpheme facilitation [7-9]. Copula is appears to initiate the acquisition of the rest of the tense and agreement system with emergence around age 2 and $90 \%$ mastery at around age 4 and a half $[4,10]$.

As with the other tense and agreement morphemes, children have often been described as using copula forms optionally before gradually reaching mastery [1]. However, more recent evidence suggests that correct uses are followed by omissions $[11,12]$. This pattern resembles the common observation that children use irregular past tense correctly (i.e., went) before going on to produce classic overregularizations (i.e., goed; [13]). Evidence from spontaneous data reveals that the copula is characteristically absent from typically developing children's first obligatory contexts (e.g., It mine; You hungry). Then, children use copula forms correctly in highly predictable frames such as it's or that's. These uses, which are technically correct, coincide with omissions in other utterances in the same conversation. Omissions are then gradually replaced with the use of copula forms in combination with novel subjects (e.g., That elephant is in).

\section{Limited scope formulae}

It's and that's are examples of a phenomenon known as limited scope formulae. Limited scope formulae (LSF) are stereotypical phrases that are used by rote automatically [14]. Braine [14] described children's initial word combinations like these as a "constant-plus-variable" providing the examples "it's a X" and "there's a X" (p. 27). He explained that these formulae are limited in scope in that children use them for expressing very specific meanings only, for example, identifying something. Put another way, children's earliest uses of grammatical morphemes such as the copula are produced without a true syntactic representation [8]. Instead, they are produced via a direct connection between the referent and phonetic content [15]. Certain fixed, stereotypical uses of copula forms are frequently heard in the parent input. Very often, these LSF-like combinations are pronominal subjects such as what or that combined with contracted forms of copula is. Children may begin to produce segments such as what's and that's without true knowledge of the syntactic, semantic, and phonological features of the copula before an abstract representation plays a role in their productions. In this case, children are not using their own grammatical systems productively. The term productivity refers to children's use of grammatical structures generated from their own grammatical knowledge $[16,17]$. To develop grammar, uses of LSF must be replaced with productive subject+copula combinations. When this occurs, children use more creative (i.e., lower frequency) subjects and predicates, marked by a shift from pronouns to lexical NPs [8].

Traditional developmental measures of tense and agreement marking have not always accounted for the transitional period from productions taken directly from the input to productions generated by a productive, abstract system. Percent accuracy is a widely used method for measuring children's knowledge of tense and agreement marking $[4,18]$. Accuracy is a rather stable measure revealing gradual growth of grammatical knowledge when used with children who have demonstrated sufficient emergence of tense and agreement morphemes in a range of sentence types, particularly past age 4 $[19,20]$. However, stability in scores is not observed when accuracy is used to measure tense and agreement marking when omissions are still present in children's utterances. For the average child, tense and agreement morphemes are largely absent before age 2 [10]. When children initially use the copula in LSF they have heard in the input (e.g., It's mine), a temporary increase in tense marking accuracy is observed $[11,12]$. As a result of tense and agreement morpheme omissions, accuracy scores subsequently drop as toddlers generate sentences independently of fixed phrases pulled from the input (e.g., This book_mine).

Productivity scores are an alternative for measuring grammatical development in very young children $[21,22]$. Measures of productivity emphasize the significance of children's combination of subjects and finiteness morphemes instead of measuring only the functional morphemes themselves as accuracy scores do. The emphasis on the subject+morpheme combinations recognizes that accuracy scores may be inflated by finiteness morphemes that are paired with high frequency, repeated subjects (e.g., it's, that's). Hadley and colleagues have used productivity measures to track the early development of tense and agreement morphemes [21-23]. These measures, such as the tense and agreement productivity (TAP) score, are more conservative than percent accuracy in crediting the child only once for the first instance of a subject+morpheme or verb+morpheme combination but not for subsequent uses 
and by capping the total uses of any of the morphemes at five. In the TAP score, "she is" and "the teacher is" are sufficiently unique, and "cow walks" and "cow walked" are sufficiently unique. An advantage to productivity measures over accuracy measures for very young children is that they capture the onset of utterances that children generate from their own grammars as opposed to awarding credit for tense morphemes learned from LSF.

\section{Children's uptake of parent input}

Previous explorations of children's acquisition of copula forms revealed that parents' provision of grammatical structures is related to children's subsequent use of the same structures $[24,25]$. However, it is important to understand the influence of parent copulas beyond solely the number of occurrences in the input. Certain instances of grammatical morphemes in parent input may be more helpful for children's grammatical growth than others. For example, child-directed auxiliaries in parents' genuine, information-seeking questions are more useful than the same auxiliaries in test questions [26]. Likewise, children make differential use of copula input based on whether the form precedes or follows the sentence subject (i.e., questions vs. declaratives; $[27,28]$ ). Thus, children do more with input than just track the number of exposures to a structure. Their uptake from the input differs from exposure to exposure of a morpheme.

This leads us to consider in what ways parents and clinicians could provide copulas that will best take advantage of children's learning strategies. For one, when adults use copulas with lexical NP subjects, those subjects are more likely to have concrete referents in the environment than pronominal subjects are. Further, using lexical NP subjects may yield morpheme boundaries that are easier for children to detect because the transitional probability between the subject and the copula is lower [29]. On the other hand, LSF (e.g., that's) have relatively higher transitional probabilities between the subject and the copula, obscuring the morpheme boundary. Lastly, uses of the full form of copula is are more acoustically salient than contracted copulas because the formant frequencies of the vowel nucleus make the syllable more audibly noticeable [30]. In input resembling LSF, contracted copulas (i.e., it's instead of $i t i s$ ) are lower in phonetic salience and reduced to an acoustically shorter duration.

Children who hear parent copulas that resembles LSF more often than their peers may be particularly susceptible to relying on LSF when they attempt copulas themselves. As a result of reliance on the input, these children may use fewer unique subjects with copulas and fewer copula conjugations (e.g., am, were). This possibility is important to explore for two reasons. First, if structural properties of copula input relate to children's copula growth, we will better understand how children make use of different forms of input. Second, overestimation of grammatical knowledge may be especially likely for children whose copula use is produced by rote and not produced through grammatical encoding. Therefore, an investigation of the relationship between parents' use of copulas in LSF-like constructions and children's subsequent propensity for unique subject+copula combinations would not only help us understand what forms of parent copulas best facilitate uptake. Such an investigation would also shed light on whether traditional measures of grammatical development are more likely to over credit some children's grammatical knowledge. To be clear, we recognize that parents are aware of morpheme boundaries when using input such as what's and that's. We refer to this input as LSF here for convenience because this input is highly reminiscent of the child utterances Braine [14] described as being formulaic and limited in their scope.

The extant literature leaves a gap in our understanding of the role of parent LSF on children's copula acquisition. Some previous studies have either measured productivity for the entire suite of tense and agreement morphemes or have quantified only copulas in parent and children's utterances. Rispoli et al. [31] found that a productivity score inclusive of multiple tense/agreement morphemes was a stable, valid measure of children's grammatical growth and a predictor of subsequent tense/agreement accuracy. Hadley et al.s [32] investigation revealed that finiteness information in parent input was related to children's overall finiteness productivity. This suggests that a study homing in on copula is, the morpheme that initiates the tense and agreement system, may also uncover valuable relationships. Rispoli et al. [27] classified parent copulas by full or reduced form and by clausal position, finding that the intersection of full form copulas and declarative structure was positively related to children's later copula is productivity.

\section{The current study}

The current study seeks to build upon the findings of previous studies by classifying parent copula forms into one of two categories based on both the structure of each copula and the subjects combined with each copula. This study additionally builds upon previous uses of productivity scores as a way of 
determining children's progress toward mastery (i.e., true learning; [21,22,31]). This is accomplished by measuring all of children's unique subject+copula combinations (e.g., These guys are red) with no caps on the number that can be credited and without restricting credit to only the use of $i s$. To understand what types of parent input contribute to children's cross-morpheme facilitation, the outcome measure should include uses of the structure in question (i.e., copula) across person and number agreement combinations (e.g., are, was) and not only forms that children used exactly as parents had used them (e.g., is, it's). Therefore, this study is expected to contribute new information to our understanding of copula development by classifying parent copula use in a new way and by measuring children's copula productivity in a way that will avoid the potential for ceiling effects and in a way that reveals progress across the entire copula system. Specifically, this investigation is expected to provide insight into how children transition from using copula is exactly as it is heard in parent input to using copula forms productively in original sentences. The rationale for the focus on third person singular copula is as opposed to am, are or past tense forms is threefold. First, is occurs more frequently in parent input than other copula forms $[32,33]$. Second, young children productively use copula is before other tense and agreement morphemes [31]. Since copula is acquisition occurs relatively early, a measure of productive use allows us to better understand the role of input in children's initial emergence of the tense and agreement system [5]. Third, each copula form that is contractible to a subject (i.e., is, am, are) has a unique phonetic form. Third person singular is productions are reduced in phonetic form because of contraction to the high frequency sibilant sound [s], whereas am and are when contracted, are reduced to sonorants, which are easier to perceive [30]. Each instance of $i s$ in parent input will be examined for the presence of contraction to the sentence subject (i.e., is or 's). Next, the subjects combined with each copula is will be classified as one of two types, pronominal or lexical.

The following research questions are addressed:

1. How does the structure of parent copula forms vary as characterized by contraction and subject type?

2. How does this variation relate to children's growth in subject-copula productivity?

Based on previous literature, we predict that parent copulas that are either contracted or combined with a high frequency pronoun (i.e., LSF copulas) will outnumber parent copulas that are either uncontracted or combined with low frequency, lexical NP subjects (i.e., non-LSF copulas). Next, LSF copulas are expected to be negatively related to children's growth in unique subject+copula combinations (i.e., USC) just as children are beginning to use copula forms productively. On the other hand, non-LSF copulas (e.g., The tea is ready; The diamond's yours?) are expected to be positively related to children's growth in USC.

\section{METHODS}

\section{Participants}

Participants included 11 mothers and their typically developing, monolingual, English-speaking children (6 male and 5 female children). The transcripts were acquired from the Child Language Data Exchange System (CHILDES), an online database of donated language transcripts [34]. Ten children's transcripts were selected from the Manchester corpus of CHILDES because the research questions in the current study required dense, longitudinal sampling. Samples in the Manchester corpus were collected by Anna Theakston and colleagues for a longitudinal study of 2- to 3-year-old typically developing children acquiring British English [35]. The children whose transcripts were used were Anne, Aran, Carl, Dominic, Gail, Joel, John, Liz, Ruth, and Warren. Two children in the Manchester corpus, Becky and Nicole, were excluded because their language samples began too late for the present research questions (i.e., 24 months of age). To compensate for this exclusion, Nina, the only child in the Suppes corpus, was added because her language samples were collected beginning at a similar age to the rest of the Manchester corpus with even denser sampling and with recordings that importantly were the same duration as the Manchester recordings [36]. In both the Manchester and Suppes corpora, children were audiotaped for 1-hour language samples while engaging in normal play activities with their mothers in their homes. Families were reported to be of middle-class SES, but as parent age and educational level were not primary measures in the original studies, that information is not reported.

The present study used donated transcripts of language samples that were collected when the children were 23, 27, and 33 months old. Mothers' utterances were analyzed when the children were 23 months old, which was the earliest measurement point for which all children had an available transcript. Because parents increase the complexity of their input in response to their children's development, it was important to analyze input as early as possible to reduce the likelihood 
that parents' copula use was influenced by their children's utterances. Child utterances were analyzed when the children were 27 months (mean MLU=2.62) and 33 months (mean MLU=3.13) old.

\section{Coding \\ Parent utterances}

In both corpora, all complete, spontaneous, and fully intelligible child-directed utterances had been previously transcribed. To answer the first research question and describe parents' variation in use of copulas, the second author examined all parent utterances for the presence of copula $i s$ and applied codes to each instance to quantify the number of LSF copulas and non-LSF copulas.

Coding procedures gave particular attention to coding only copula forms and not other forms of contracted 's such as possessive (e.g., Mommy's book) or the auxiliaries is, does, or has (e.g., Mommy's trying; What's the duck say?; Mommy's got some). All copulas were coded in multiclausal utterances (e.g., Mine is blue and yours is green). Sentence subjects were identified to determine whether each copula had been combined with a pronominal or lexical subject. To determine the subject of questions, the subject and verb were inverted to transform the sentence into declarative word order (e.g., "Where is the tiny one?" into "The tiny one is where"). For passive sentences (e.g., The basket's held up by the balloon), the NP to the left of the copula was considered the subject rather than the NP performing the thematic role of agent. Because only the third person singular present tense form of the copula (i.e., is) was examined in this study, all subjects were accordingly third person singular subjects (e.g., it, the rabbit).

Each parent use of third person singular copula received one of two codes. The first code, LSF, was added to parent uses of third person singular copula that were contracted to pronominal subjects (e.g., It's not ice cream). Subjects were considered pronominal if they were personal pronouns (e.g., it, he, she, mine, yours, theirs) or demonstrative pronouns (e.g., this, that).

The second code, non-LSF, was used when the copula either appeared in its full, uncontracted form (i.e., is) or was combined with a lexical NP subject, or both. Subjects were considered lexical if they included a noun that was an openclass, content word (e.g., truck, dolly). Lexical NPs could include determiners (e.g., my bracelet; that way; this one) or modifiers (e.g., the little dolphin) with no restrictions on expansions (e.g., a great big gap) or recursion (e.g., the man driving the car). The non-LSF code was used for sentences with lexical NP subjects combined with isn't. Although isn't contains a contraction, the copula itself is not reduced (e.g., This dress isn't on right).

\section{Child utterances}

All spontaneous, complete, and fully intelligible child utterances were coded by the second author in transcripts of samples collected when children were 27 and 33 months. All forms of copula BE (i.e., is, am, are, was, were) were identified, including contracted forms (e.g., it's).

\section{Measures}

The first two parent measures were the number of LSF copulas and the number of non-LSF copulas. Since the sampling time was held constant at 1-hour long, frequencies of parent copula use could be used. The overall amount of copulas heard by each child may affect his or her copula acquisition, so frequencies were preferred to proportions for the correlations described below. Using proportions, for example dividing LSF by all copula use or total utterances, could have obscured each parent's level of general talkativity [37]. Proportions of LSF copulas out of all copulas are provided for descriptive purposes only.

The three child outcome measures were USC at 27 months, USC at 33 months, and the growth in USC between 27 and 33 months (i.e., a difference score calculated by subtracting USC at 27 months from USC at 33 months). First, all utterances coded as containing a copula were listed. From there, unique combinations of subject+copula were counted. See Figure 1 for a sample calculation with all uses of copula forms from one child, Anne. Children were only given credit for combinations that were likely to have been produced productively [cf. 31]. To receive credit as a unique combination, copula forms of am, is, are, was, and were needed to be either uncontracted (e.g., The fringe is lots of colors; Anne, 33 months) or contracted to a lexical NP subject (e.g., The light's on; Aran, 33 months). Combinations were only counted once so that children were not credited multiple times for repeated identical combinations ("There you are" and "Here you are"; Liz, 33 months). A subject could be repeated if a different form of copula was used (e.g., It is vs. It was; Nina, 33 months). A copula form could be repeated if combined with a different subject (e.g., train is vs. elephant is; Carl, 33 months). The unique uses were then totaled at each of the two measurement points. Finally, the difference in USC between the two mea- 


\begin{tabular}{|c|c|}
\hline All utterances with copula & Unique subject + copula combinations credited \\
\hline \multicolumn{2}{|c|}{27 months } \\
\hline What is that? & 1. That + is \\
\hline That is not right. & 2. It + is \\
\hline There it is. & 3. This + is \\
\hline Is it all gone? & 4. You + are \\
\hline $\begin{array}{l}\text { This is my Christmas present. } \\
\text { Is it now my birthday? }\end{array}$ & 5. They + are \\
\hline Where are you? & $=5 \mathrm{USC}$ at 27 months \\
\hline They are. & \\
\hline This is in there. & \\
\hline \multicolumn{2}{|c|}{33 months } \\
\hline These ones are orange. & 1. These ones + are \\
\hline Who is other James? & 2. Other James + is \\
\hline These are babies. & 3. These + are \\
\hline The fringe is lots of colors. & 4. The fringe + is \\
\hline This is her box. & 5. This + is \\
\hline And he is now. & 6. $\mathrm{He}+$ is \\
\hline There he is. & 7. That one + is \\
\hline And that one is. & 8. Mines + is \\
\hline And these ones are. & 9. $\mathrm{I}+\mathrm{am}$ \\
\hline And mines is. & 10. $\mathrm{We}+$ are \\
\hline \multicolumn{2}{|l|}{ Am I? } \\
\hline Here we are. & $=10$ USC at 33 months \\
\hline
\end{tabular}

Figure 1. Sample calculation of growth in USC for Anne. The first occurrence of each unique subject+copula combination is bolded. Credited combinations are numbered to illustrate scoring.

surement points was calculated to measure the growth in children's copula productivity.

\section{Reliability}

Reliability was established for parent LSF copulas, parent non-LSF copulas, and child copulas. Reliability was established for parent coding through a calculation of inter-rater agreement. After the second author coded all parent utterances, the first author randomly selected three of the 11 transcripts and independently coded them resulting in percent agreement values of $99.4 \%, 97.1 \%$, and $97.5 \%$. To establish coding reliability for children's uses of copulas, the first author checked every copula code in child utterances and examined all child utterances without a copula code to ensure no instances had been missed. Three changes were made across the 27-month transcripts and eight changes were made across the 33-month transcripts out of 52 and 161 total copula uses, respectively. All changes were instances of auxiliaries that had been incorrectly coded as copulas. Lastly, the first author examined the scores that the second author had assigned to each child for USC at both 27 and 33 months. Disagreements on the copula uses credited as USC were resolved through consensus.

\section{Analyses}

To address the first research question, variability in the structure of the copulas parents directed to their children was characterized. Mean, standard deviation, and range were determined for each of the three parent measures and each of the three child measures.

To address the second research question, how parent copulas related to children's subsequent growth in subject-copula combinations, two Pearson product-moment correlations were run. The first correlation was between parents' use of LSF copulas and children's six-month growth in USC. The second was between parents' use of all other third person singular copulas (i.e., non-LSF) and children's six-month growth in USC. To confirm that a Pearson correlation was appropriate for detecting a relationship between parents' copula input and children's growth in USC over six months, we first determined 
Table 1. Individual data and descriptive statistics for parent copulas, child USC, and 6-month growth

\begin{tabular}{|c|c|c|c|c|c|c|}
\hline & \multicolumn{3}{|c|}{ Parent copulas at 23 months } & \multicolumn{3}{|c|}{ Child USC } \\
\hline & LSF & Non-LSF & Copula is & 27 months & 33 months & 6-mo Growth \\
\hline Anne & 90 & 35 & 21 & 5 & 10 & 5 \\
\hline Aran & 205 & 173 & 78 & 2 & 22 & 20 \\
\hline Carl & 142 & 29 & 19 & 4 & 10 & 6 \\
\hline Dominic & 126 & 44 & 24 & 2 & 10 & 8 \\
\hline Gail & 161 & 126 & 96 & 2 & 9 & 7 \\
\hline Joel & 107 & 54 & 53 & 2 & 4 & 2 \\
\hline John & 94 & 53 & 34 & 5 & 3 & -2 \\
\hline Liz & 111 & 49 & 23 & 5 & 13 & 8 \\
\hline Nina & 223 & 147 & 90 & 6 & 17 & 11 \\
\hline Ruth & 155 & 95 & 76 & 0 & 3 & 3 \\
\hline Warren & 122 & 131 & 66 & 4 & 5 & 1 \\
\hline$M$ & 139.6 & 85.1 & 52.7 & 3.36 & 9.63 & 6.27 \\
\hline$S D$ & 43.4 & 51.1 & 28.3 & 1.86 & 6.00 & 5.87 \\
\hline
\end{tabular}

LSF, limited scope formulae; USC, unique subject+copula combinations; Copula is, total parent uses of third person singular copula is.

that each variable followed a normal distribution using a Q-Q probability plot. We then confirmed that the assumption of bivariate normality was not violated [38,39]. For the two-tailed tests, the correlation significance level was set at 0.05 .

\section{RESULTS}

On average, in one-hour samples of input directed to their children at 23 months, LSF copulas outnumbered non-LSF copulas (i.e., $M=139.6, S D=43.4, R=90-223$ vs. $M=85.1$, $S D=51.0, R=29$-173; Table 1). In other words, parents used copula is contracted to pronominal subjects more than other uses of copula is (i.e., with a lexical subject or uncontracted). When considered as a percentage of all forms of is directed to children, forms contracted to pronominal subjects accounted for $64.5 \%$ of parent copula is, on average. One parent's use of is contracted to pronouns accounted for $83.0 \%$ of all her 23 month uses. For all parents, provision of $i$ contracted to pronoun subjects accounted for at least about half of $i s$ use (i.e., $\min =48.2 \%)$. Most of the eleven children $(n=10)$, excluding Ruth, were using copula forms in combination with lexical NP sentence subjects at 27 months. At this measurement point, children on average produced 3.36 unique subject+copula combinations ( $S D=1.86$; Table 1). Children's variability in unique subject+copula combinations increased over time. Whereas the average number of unique combinations at 33 months had increased to 9.63 , the standard deviation had no- ticeably increased to 6.00 . This change indicates that at 27 months, children were more similar to one another in the number of subject+copula combinations produced, with the maximum number of combinations at six. At 33 months, however, one child produced 22 unique combinations. On average, children increased the number of unique combinations produced by 6.27 , with a maximum change of 20 additional combinations between 27 and 33 months and with all but one child demonstrating growth.

Pearson correlations revealed differences in how each of the two types of parent copula related to the difference in children's number of USC between 27 and 33 months (i.e., growth in USC). First, there was no significant relationship between parents' use of LSF and children's growth in USC over 6 months ( $r=0.534, n=11, p=0.091)$. However, there was a strong positive correlation between other instances of parent copula is (i.e., non-LSF and children's growth in USC; $r=0.729$, $n=11, p=0.011)$.

\section{DISCUSSION}

In this study, we explored how parents differ from one another in provision of copulas directed to their toddlers when children are just beginning to produce the copula themselves. Further, we asked how parent copula provision relates to children's subsequent growth in copula productivity when the structure and linguistic environment of the copula are consid- 
ered. Our hypotheses about the relationships between parent and child measures were mostly supported by Pearson correlations. The relationship between parent use of LSF-like copula and children's later unique combinations of subjects and copulas was non-significant. That is, parents' use of LSF-like copula input was not related to children's copula productivity. On the other hand, parent use of non-LSF copulas was.

These results are important firstly to our general understanding of parent input characteristics and secondly to how children take advantage of input for learning individual grammatical morphemes. Recall that parents varied in how many of their child-directed uses of $i s$ were contracted to pronominal subjects. Some parents' provision of is was more evenly split between instances contracted to pronouns and other instances (i.e., uncontracted or lexical contractions), whereas other parents contracted is to high frequency pronoun subjects up to $80 \%$ of the time. Despite this variation, a primary finding of this study was that generally parents used pronominally contracted copula is (e.g., it's, that's) more often than all other subject+copula is combinations (e.g., The tiger's; The tiger is). This type of LSF input could be less helpful to children whose own use of copulas is just emerging. First, when copulas are contracted to pronouns, the sentence subject is less likely to have a concrete referent. Second, high frequency combinations are more difficult to segment using statistical learning. Third, LSF copulas are phonetically reduced in that the vowel portion of the word is is not phonetically realized. Taken together, these observations may explain why the use of input such as it's, what's, that's and the like were unrelated to children's growth in copula productivity. Even though the non-LSF copulas included some contractions, all contractions included in this measure were lower frequency lexical noun phrase subjects. In those instances, it seems possible that the rarity of the subject afforded easier segmentation from the copula.

Not all copulas in parent utterances were related to children's copula growth over six months. Only non-LSF copulas were related to children's growth. It is possible that parents generally use enough non-LSF out of all copulas for frequencybased measures to have been significantly related in early correlational studies. That is, it has already been established that the amount of parent talk is positively related to a variety of child outcomes [25]. Yet, this study predicted that a particular structure (i.e., copula) in a specific context (i.e., non-LSF) would be more useful to children than in other contexts (i.e., LSF). We based this prediction on both statistical learning theory and current theoretical explanations for children's gradual development of morphosyntax [8]. Our measures went beyond only counting copulas in parent input and again in children's utterances. By quantifying parent copulas with consideration for the presence of contraction and for the subject type, and by only counting uses of children's copulas likely to reflect productive grammatical knowledge, this study uncovered a relationship between measures. Specifically, children who heard more non-LSF copulas demonstrated greater growth in copula productivity between 27 and 33 months of age, but children whose parents used a great deal of LSF copulas did not necessarily demonstrate growth. Based on these results, it seems possible that non-LSF copulas in the input are easier constructions for children to analyze than copulas in LSF.

The results of this study align well with more recent investigations into relationships between parent and child copula use. Rispoli et al. [27] also considered the presence of contraction in parent copula is by coding uses as full or contracted and considering how each of those types interacted with syntactic position. Some full (i.e., uncontracted) parent copulas positively related to children's later use of $i$, but only when appearing in declarative sentences. Rispoli et al. [27] did not classify parent subjects with copulas as pronominal or lexical as we have here, but their finding that parent copulas in whquestions negatively related to children's use of $i s$, is highly compatible with our own finding that pronominally contracted parent copulas did not support children's general (i.e., all conjugations) copula productivity. Rispoli and Hadley [28] measured copulas in parent input and in children's utterances in different ways than we have here, yet also found relationships between measures that are congruent with the present findings. They reported that greater diversity in the words surrounding copula is in parent input was positively related to children's is productivity. In the present study, we classified the subjects that parents combined with is more narrowly, as pronominal or lexical, to home in on exactly what types relate to child outcomes. It is logical that our findings resemble those of these prior investigations, because using pronoun subjects can only increase the diversity of subject types to a limited degree, but parents can combine an infinite number of unique subject types with copulas when using lexical NP subjects. Overall, these findings are more supportive of explanations of language growth centering on gradual expansion of a unified tense marking system through the acquisition of abstract features. Our parent measure included only third singular copula is, but it was positively related to the outcome mea- 
sure, which included all of children's unique uses of copulas including am, are, is, was, and were. Thus, our results provide support for the notion of cross-morpheme facilitation $[7,8]$.

This study did not directly test predictions of alternative accounts that center on one-by-one abstraction of morphemes from input. Constructivist views posit that much of children's initial uses of grammatical morphemes occur in lexically specific constructions which they have heard in parent input [40]. In our study of children who were just beginning to use the copula, we did not credit children for the very copula constructions that made up the majority of their parents' copula input (e.g., that's, what's). Despite this, children's gains in a measure of all forms of the copula was related to a parent measure that only included $i s$, and that was taken at a time preceding children's expansion of the copula into multiple types (e.g., am, were). In other words, parent provision of third singular present tense copulas was positively related to a measure of children's copula use in all person and number intersections. Based on classic studies showing relationships between parent and child use of grammatical structures, it is likely that either or both parent measures (i.e., LSF and nonLSF copulas) are related to children's growth in their own use of copula is, whether contracted or uncontracted [25]. However, since much of children's copulas are rote-like, performing this analysis would not move us as a field toward understanding what type of input promotes children's productive uses of the copula.

In situating these findings with other studies of English acquisition, we must address the relevance of the mothers' dialect. Tag questions (e.g., It's yours, isn't it?) are prevalent in some dialects of British English [41]. The potentially high frequency of isn't raises the question of how children acquiring British English make use of transitional probabilities to sentence elements following is including predicate NPs or pronouns, modifiers, and negation words. As the present study focused on the transition from subject to copula and the majority of copula forms occur in active declarative clauses, narrowing in on the transition from copula is to the word following it was outside the study's scope. An investigation of this kind should give special attention to the phonetic production of isn't in tag questions rather than relying on orthographic transcriptions so that instances of innit, used in some varieties of British English, can be detected and classified appropriately.

\section{Methodological and clinical implications}

First, the results of this study contribute new information to- ward explaining previous methodological challenges in the measurement of children's grammatical growth. Specifically, the findings shed light on why some children's tense/agreement marking accuracy appears to decline over time then increase again. Pine et al. [40] measured the accuracy of tense and agreement morphemes in the Manchester corpus (i.e., the majority of participants in the present study). Of the children included in both the present study and in Pine et al. [40], Anne, Aran, and Warren demonstrated such a pattern of temporary decline in copula accuracy scores, yet all three demonstrated growth in USC, a productivity score, as did seven of the other eight participants (see also [31]). Scores dropping over time then later increasing is inconsistent with the gradual development observed in productivity scores. It is possible that the children whose parents used the highly frequent pronominally contracted LSF copula (e.g., it's, that's) are susceptible to measurement error $[11,31]$. Specifically, children's grammatical knowledge may be more likely to be overestimated, as indicated by inflated accuracy scores, when their parents provide tense information that is highly formulaic and phonetically reduced. Therefore, the findings of this study could help identify children for whom this type of measurement error is likely to be observed.

The findings of the current study also hold implications for both parents and clinicians working with children at risk for delayed acquisition of tense and agreement morphemes. We suspect that LSF copulas are especially likely to appear in test questions (e.g., What's this called?). If a future study confirmed this, parents and clinicians could be encouraged to comment on the environment. Commenting should have the effect of proportionally reducing test questions and increasing the combination of names for things with third person copulas (e.g., The bowl is full; [33,42]). Adults' input of copula forms is more likely to resemble LSF simply by virtue of using pronouns as subjects because copulas are more likely to be contracted when the subject is a pronoun such as it or that $[43,44]$. On the other hand, providing explicit information about objects and surroundings with lexical NP subjects could promote growth in USC by decreasing children's reliance on rote memorization. Recent work has provided evidence that when parents are taught to increase the diversity of their own sentence subjects through other-focused commenting, their children later use more diverse third person subjects themselves and use more adult-like tense and agreement marking compared to peers $[45,46]$. 


\section{Future directions}

There is room for further refinement of our parent measure. First, we do not know if one type of the non-LSF copula (i.e., uncontracted or lexically contracted) drove the correlation between parent input and child outcomes. A finer-grained coding scheme could detect a more precise relationship. Second, future research could explore specifically which types of uncontracted (i.e., full form) copula is are most helpful for children learning grammar. In the present analyses, we collapsed all full forms together. It is possible that some full forms are more helpful than others based on word order or sentence position (cf. [28]). To our knowledge, no researchers have quantified the relative frequency of different types of full form copula is in the input of British English-speaking parents, which may significantly differ from American English in copula provision because of highly frequent tag questions.

A future study could take advantage of the methodological benefits of productivity scores to address the debate regarding whether children's initial knowledge of copulas and auxiliaries is restricted to lexically-specific constructions. Wilson [44] reported that Nina [36] and Adam [24] each demonstrated very different rates of provision for morphemes across pronoun subjects (i.e., He's vs. I'm). Pine et al. [40] addressed this discrepancy taking participants' knowledge of individual morphemes into account. They reported that children in the Manchester corpus had higher copula accuracy with it and he subjects than with $I$ subjects. A future investigation could explore the stability of specific subject+copula constructions with a productivity-like score to address this question without the pitfalls of accuracy scores. Such an investigation could uncover whether cross-morpheme facilitation is present or if instead children's use of copula morphemes relates to parent provision of those copula forms specifically.

Lastly, the children in the current study were typically developing and the sample size was relatively small, so future work is needed to explore how parent copulas relate to children's growth in USC in at-risk populations. Furthermore, socioeconomic status was not a primary consideration during recruitment of the Manchester or Suppes corpora. As families were middle-class, we are limited in generalizing these results to other family backgrounds.

\section{CONCLUSION}

Overall, this study has provided evidence that English-speaking parents of toddlers do not all use copula is in the same types of sentences. Some parents were far more likely to use copula is with low-frequency subjects or without contraction. The study also substantiated the notion that children do more with grammatical morphemes in the input than merely take statistics on the frequency of occurrence. Furthermore, this study indicated that not all copulas in parent input are equally helpful. Some uses benefit children more, facilitating gains in using the copula more creatively, as demonstrated by children's combining copula forms with a variety of subjects. Children with parents who used low-frequency subjects and uncontracted copula forms expanded their own use of the copula across person, number, and tense combinations more than their peers who heard more LSF-like copulas used in the input. Investigations of parent provision of grammatical morphemes should be sure to consider both the phonetic form of tense morphemes and the structure of the sentences in which they appear. Such examinations of children's language development should also consider measures of growth that display stable increases over time. Only by carefully classifying input and by using appropriate measures can relationships between input and grammatical growth be better understood.

\section{AUTHORS' DISCLOSURES OF POTENTIAL CONFLICTS OF INTEREST}

This research was supported by the Bowling Green State University College of Health and Human Services Linda Petrosino PILLARS Fund, the BGSU Department of Communication Sciences and Disorders, and the BGSU Graduate College.

\section{CONFLICT OF INTEREST}

The authors declare that they have no conflict of interest. Portions of this work were presented at the American SpeechLanguage Hearing Association convention in Denver, Colorado, USA in November 2015.

\section{REFERENCES}

1. Wexler K. Optional infinitives, head movement and the economy of derivations. In: Lightfoot D, Hornstein N, editors. Verb movement. Cambridge: Cambridge University Press; 1994. p. 305-350.

2. Leonard LB. Children with specific language impairment and their contribution to the study of language development. J Child Lang. 2014;41:38-47.

3. Guasti MT. Language acquisition: The growth of grammar. 2nd ed. Cambridge: The MIT Press; 2016. 
4. Rice ML, Wexler K, Hershberger S. Tense over time: The longitudinal course of tense acquisition in children with specific language impairment. J Speech Lang Hear Res. 1998;41:1412-1431.

5. Rispoli M, Hadley PA, Holt JK. Sequence and system in the acquisition of tense and agreement. J Speech Lang Hear Res. 2012;55: 1007-1021.

6. Hadley PA, McKenna MM, Rispoli M. Sentence diversity in early language development: Recommendations for target selection and progress monitoring. Am J Speech Lang Pathol. 2018;27:553565.

7. Leonard LB, Camarata SM, Brown B, Camarata MN. Tense and agreement in the speech of children with specific language impairment: Patterns of generalization through intervention. J Speech Lang Hear Res. 2004;47:1363-1379.

8. Rispoli M, Hadley P. Toward a theory of gradual morphosyntactic learning. In: Arnon I, Clark EV, editors. Experience, variation, and generalization: Learning a first language. Amsterdam: John Benjamins Publishing Company; 2011. p. 15-33.

9. Rispoli M. Cross-morpheme facilitation: The systematic emergence of agreement in 2-year-olds. Lang Acquis. 2016;23:293-306.

10. Radford A. Syntactic theory and the structure of English: A minimalist approach. Cambridge: Cambridge University Press; 1997.

11. Fitzgerald C, Rispoli M, Hadley P, McKenna M. Productivity scoring as a metric of early finiteness marking. Poster presented at: Symposium on Research in Child Language Disorders; 2012; Madison, WI.

12. Leonard LB, Haebig E, Deevy P, Brown B. Tracking the growth of tense and agreement in children with specific language impairment: Differences between measures of accuracy, diversity, and productivity. J Speech Lang Hear Res. 2017;60:3590-3600.

13. Marcus GF, Pinker S, Ullman M, Hollander M, Rosen TJ, Xu F. Overregularization in language acquisition. Monogr Soc Res Child Dev. 1992;57:1-178.

14. Braine MD. Children's first word combinations. Monogr Soc Res Child Dev. 1976;41:1-104.

15. Bock K, Levelt WJ. Language production: Grammatical encoding. In: Gernsbacher MA, ed. Handbook of psycholinguistics. San Diego: Academic Press; 1994. p. 945-984.

16. Berko J. The child's learning of English morphology. Word. 1958; 14:150-177.

17. Tomasello M. First verbs: A case study of early grammatical development. Cambridge: Cambridge University Press; 1992.

18. Bedore LM, Leonard LB. Specific language impairment and grammatical morphology: A discriminant function analysis. J Speech Lang Hear Res. 1998;41:1185-1192.

19. Gladfelter A, Leonard LB. Alternative tense and agreement morpheme measures for assessing grammatical deficits during the preschool period. J Speech Lang Hear Res. 2013;56:542-552.

20. Rispoli M, Hadley PA. Let's be explicit about the psycholinguistic bases of developmental measures: A response to Leonard, Haebig, Deevy, and Brown (2017). J Speech Lang Hear Res. 2018;61: 1455-1459.

21. Hadley PA, Short H. The onset of tense marking in children at risk for specific language impairment. J Speech Lang Hear Res. 2005; 48:1344-1362.

22. Hadley PA, Rispoli M, Holt JK, Fitzgerald C, Bahnsen A. Growth of finiteness in the third year of life: Replication and predictive validity. J Speech Lang Hear Res. 2014;57:887-900.

23. Hadley PA, Holt JK. Individual differences in the onset of tense marking: A growth-curve analysis. J Speech Lang Hear Res. 2006; 49:984-1000.

24. Brown R. A first language: The early stages. Cambridge: Harvard University Press; 1973.

25. Furrow D, Nelson K, Benedict H. Mothers' speech to children and syntactic development: Some simple relationships. J Child Lang. 1979;6:423-442.

26. Hoff-Ginsberg E. Function and structure in maternal speech: Their relation to the child's development of syntax. Dev Psychol. 1986;22:155-163.

27. Rispoli M, Papastratakos T, Stern C, Hadley P. Input Packaging and the Acquisition of Copula is. Oral presentation at the Symposium for Research in Child Language Disorders; 2015 Jun; Madison, WI.

28. Rispoli M, Hadley P. Input effects on the acquisition of finiteness. In Chu C, Coughlin C, Prego BL, Minai U, Tremblay A, editors. Proceedings of the 5th Generative Approaches to Language Acquisition North America. Somerville, MA: Cascadilla Press; 2014. p. 121-127.

29. Saffran JR. Statistical language learning: Mechanisms and constraints. Curr Dir Psychol Sci. 2003;12:110-114.

30. Koehlinger K, Owen Van Horne A, Oleson J, McCreery R, Moeller MP. The role of sentence position, allomorph, and morpheme type on accurate use of s-related morphemes by children who are hard of hearing. J Speech Lang Hear Res. 2015;58:396-409.

31. Rispoli M, Hadley PA, Holt JK. The growth of tense productivity. J Speech Lang Hear Res. 2009;52:930-944.

32. Hadley PA, Rispoli M, Fitzgerald C, Bahnsen A. Predictors of morphosyntactic growth in typically developing toddlers: Contributions of parent input and child sex. J Speech Lang Hear Res. 2011; 54:549-566.

33. Fitzgerald CE, Hadley PA, Rispoli M. Are some parents' interaction styles associated with richer grammatical input? Am J Speech Lang Pathol. 2013;22:476-488.

34. MacWhinney B. The CHILDES Project: Tools for analyzing talk: Volume I: Transcription format and programs, volume II: The database. 3rd ed. Mahwah: Lawrence Erlbaum Associates; 2000.

35. Theakston AL, Lieven EVM, Pine JM, Rowland CF. The role of performance limitations in the acquisition of verb-argument structure: An alternative account. J Child Lang. 2001;28:127-152.

36. Suppes P. The semantics of children's language. Am Psychol. 1974;2:103-114.

37. Klee T. Developmental and diagnostic characteristics of quantitative measures of children's language production. Top Lang Disord. 1992;12:28-41.

38. Barnett V, Lewis T. Outliers in statistical data. New York: Wiley; 1978. 
39. Gnandesikan R, Kettenring JR. Robust estimates, residuals, and outlier detection with multiresponse data. Biometrics. 1972;28: 81-124.

40. Pine JM, Conti-Ramsden G, Joseph KL, Lieven EV, Serratrice L. Tense over time: Testing the agreement/tense omission model as an account of the pattern of tense-marking provision in early child English. J Child Lang. 2008;35:55-75.

41. Tottie G, Hoffmann S. Tag questions in British and American English. J Engl Linguist. 2006;34:283-311.

42. Hadley PA, Walsh KM. Toy talk: Simple strategies to create richer grammatical input. Lang Speech Hear Serv Sch. 2014;45:159-172.

43. Frank AF, Jaeger TF. Speaking rationally: Uniform information density as an optimal strategy for language production. Proceed- ings of the Annual Meeting of the Cognitive Science Society. 2008; 30:30.

44. Wilson S. Lexically specific constructions in the acquisition of inflection in English. J Child Lang. 2003;30:75-115.

45. Hadley PA, Rispoli M, Holt JK. Input subject diversity accelerates the growth of tense and agreement: Indirect benefits from a parent-implemented intervention. J Speech Lang Hear Res. 2017;60: 2619-2635.

46. Hadley PA, Rispoli M, Holt JK, Papastratakos T, Hsu N, Kubalanza $\mathrm{M}$, et al. Input subject diversity enhances early grammatical growth: Evidence from a parent-implemented intervention. Lang Learn Dev. 2017;13:54-79. 